\section{What Makes Pains Unpleasant?}

\section{Draft 27 October 2012} Forthcoming in Philosophical Studies

The unpleasantness of pain motivates action. Hence many philosophers have doubted that it can be accounted for purely in terms of pain's possession of indicative representational content. Instead, they have explained it in terms of subjects' inclinations to stop their pains, or in terms of pains being constituted by experiential commands. I claim that such "noncognitivist" accounts fail to accommodate unpleasant pain's reason-giving force. What I argue is needed is a view on which pains are unpleasant, motivate, and provide reasons in virtue of possessing content that is indeed indicative, but also, crucially, evaluative.

What makes pains unpleasant? Arguably, they are neither essentially nor always unpleasant. Stick a pin into the hand of someone with pain asymbolia, and while he will say he feels pain, he will also say it doesn't bother him and may even laugh or turn his hand over so you can prick the other side (Grahek 2007). But when, as typically, pains are unpleasant, in virtue of what is this the case? ${ }^{1}$

This question is made particularly interesting by two crucial features of unpleasant pains: their badness and their motivational force. Suppose you step into a bath that, being too hot, causes an unpleasant pain in your foot. This experience will be bad for you; and it will also motivate you to act, for example to lift your foot from the scalding water. These facts are crucial constraints on any account of pain's unpleasantness, constraints that take centre stage in what follows.

${ }^{1}$ For simplicity, I assume asymbolics are in pain, but none of my key claims depends on this.
To make vivid the challenge before us, we might contrast unpleasant pains with other experiences. A table's looking square to you, we might say, is neither bad for you nor good for you, nor motivational (independently of further desires). If that's right, what makes unpleasant pain different? Or, moving from vision to asymbolia, what makes normal pain different from asymbolic pain? An obvious answer is: its unpleasantness. But what is it that makes normal but not asymbolic pain unpleasant?

These putative contrasts are controversial but, if you doubt them, here is another angle on the challenge before us. Philosophers often explain crucial features of experiences-for example their phenomenally conscious character and epistemic role-by invoking their possession of indicative representational content. However, most doubt that pain's unpleasantness can be thus explained. ${ }^{2}$ I suspect the reason for this is twofold: first, we tend to understand the idea of experiences possessing such content in a way that turns them into, if not beliefs, then belief-like states, whose role is to inform the subject of how the world is; and second, lurking in many minds is the Humean idea, familiar from metaethics, that informational states simply cannot motivate, motivation being the job only of desires and their ilk. Hence it can seem that, in the case of unpleasant pain, the idea of indicative representational content-usually so explanatorily fecund-is no help at all.

In what follows, I argue against two influential views of unpleasant pain motivated by just this line of thought. And I defend instead an account that violates its strictures, an account that attempts to explain pain's unpleasantness in terms of content that is indeed indicative, but also, crucially, evaluative. But first, in the opening two sections, I get into clearer focus the challenge before us.

${ }^{2}$ If, unlike Martínez (2011), you doubt contents have moods -indicative or otherwise-you can instead frame the issue in terms of whether unpleasant pains could be "purely truthapt". See §2. 


\section{Unpleasantness, Badness, and Motivation}

\section{Consider the following:}

\section{The Hedomotive Claims}

Normativity

A1. Unpleasant pain is bad for its subject, intrinsically and defeasibly.

A2. Unpleasant pain is a justifying reason (i.e. a good reason) for avoidance behaviour, intrinsically and defeasibly.

A3. Intentionally causing unpleasant pain in another is wrong, prima facie.

\section{Motivation}

B1. Unpleasant pains are motivational states. Independently of further desires, they defeasibly motivate certain behaviour.

B2. Unpleasant pains are motivating reasons. Independently of further desires, they defeasibly rationalise certain behaviour. ${ }^{3}$

Some words of explanation. Unpleasant pains can produce all sorts of behaviour: grimacing, for instance, or taking painkillers. But I shall often focus on what I call "avoidance behaviour" - behaviour, such as lifting your foot from the scalding bathwater, that is apt to avoid or limit bodily damage. Some avoidance behaviour is mere reflex; but some, verifying B1, is motivated by unpleasant pain. Verifying B2, moreover, unpleasant pain doesn't merely cause such behaviour, but rationalises it, providing the reason for which an agent performs it. ${ }^{4}$ Unpleasant pain makes available a distinctively perspectival kind of explanation, unavailable in the case of reflexive behaviour, for instance. To explain your lifting your foot from the bathwater in terms of your unpleasant pain is to explain your action in terms of the reason for which you performed it; it is to delineate the perspective from which that footlifting seemed rational to its agent. Crucially, moreover, unpleasant pains thus motivate behaviour independently of further desires, as B2

${ }^{3}$ Versions of these claims also hold for other unpleasant experiences.

${ }^{4}$ I use "rationalise" to refer to a kind of motivating, notice, not a kind of explanation. says. If I say you lifted your foot from the bathwater because your pain was unpleasant, completeness does not require me to add that furthermore you had a desire to (say) avoid unpleasant experiences. ${ }^{5}$

Notice "defeasibly". A1 says that your unpleasant pain is bad only defeasibly: it might yet be good overall-if, say, it saves you from injury. B1 similarly says that unpleasant pain motivates behaviour only defeasibly: a stronger motivation might make you grin and bear it. And finally notice my distinction between two kinds of practical reasons: justifying reasons and motivating reasons. If the train at the platform is going where you want and need to go, yet you don't believe it is, then while there is a justifying reason (a good reason) for you to catch the train, you lack a motivating reason (a state capable of rationalising your catching it). If the train is not going where you want and need to go, but you falsely believe it is, you have a motivating reason to catch it, but there is no justifying reason for doing so. Back in the pain case, then, A2's point is that your unpleasant pain is not only a motivating reason, but also a good reason for lifting your foot from the bathwater.

Now, like many of my opponents, I find these hedomotive claims compelling. ${ }^{6}$ Hence I take them in what follows to be important constraints on accounts of pain's unpleasantness.

\section{The Humean Challenge}

To see why the hedomotive claims pose such a challenge, consider the following:

\section{Pure Perceptualism}

A subject's being in unpleasant pain consists in her undergoing a somatosensory perceptual experience

\footnotetext{
5 "Further" and "furthermore" are important. Here I am not (yet) denying that unpleasant pains are or involve desires. See $\$ 3$.
}

${ }^{6}$ See $\$ 3$ and note 19. 
that represents to her that a body part of hers is undergoing a disturbance of a certain sort. ${ }^{7}$

On this view, unpleasant pains are belief-like or, better, truth-apt. To say that a state is truth-apt is to say that it purports to represent the world in a way that makes it criticisable if false. It is, for example, held widely (though not universally, as we shall see) that desires are not truth-apt, for example that a desire to win the lottery is not criticisable if you lose. Beliefs, by contrast, are truth-apt. And so are unpleasant pains if pure perceptualism is right. For, according to pure perceptualism, unpleasant pains are perceptual experiences that, by dint of their indicative content, inform their subjects-accurately or inaccuratelythat parts of their own bodies are undergoing disturbances. Hence there is a kinship between pure perceptualism and what we might call the visual content view, according to which its looking to you as though there is a red cube before you consists in your undergoing a visual experience which, by dint of its indicative content, informs youaccurately or inaccurately - that a red cube is before you. But notice this: while many philosophers endorse something rather like the visual content view, virtually no one accepts pure perceptualism. Why not?

Because, I suggest, a Humean worry seems to stand in the way. To see this, consider an argument seemingly far removed from our concerns:

\section{Narrow Inertness Argument}

1. Moral evaluations are motivational states ${ }^{8}$

2. Judgements are not. (Narrow inertness.)

3. So moral evaluations are not purely judgements. ${ }^{9}$

7 I use "disturbance" as a place-holder for whatever bodily state the view in question takes pains to represent, for example bodily damage (Tye 1995); "disorder", defined partly in terms of the threat of bodily damage (Pitcher 1970); certain kinds of "tissue distortion" (Tye 1995b; Cutter and Tye 2011); or such microphysiological conditions as nociceptor activity (Armstrong 1968)

"See B1 above for how I am using "motivational state". "State", as I use it, includes events. ${ }^{9}$ See Hume 1739/1978 and Bricke 1996.
According to this argument, judgements (both standing beliefs and occurrent endorsements of propositions) are motivationally inert. My belief that there is a beer in the fridge will motivate me to do something only if I have a further desire-to, say, drink a beer. But moral evaluations (that is, the mental states expressed by sincere utterances of such sentences as "I should save the drowning child") are motivational. Hence, the argument concludes, moral evaluations cannot be judgements.

Whatever its merits, what has this argument to do with pain? It suggests the following parallel:

\section{Broad Inertness Argument}

1. Unpleasant pains are motivational states.

2. Truth-apt states are not. (Broad inertness.)

3. So unpleasant pains are not purely truth-apt states.

This argument arises from its predecessor simply by substituting "unpleasant pains" for "moral evaluations" and stretching the narrow inertness principle to cover not only judgements, but all truth-apt states, including any truth-apt experiences. So the idea is: pains are motivational; truth-apt experiences are not; pains cannot be such experiences, therefore, hence we must jettison pure perceptualism and indeed any account of unpleasant pain that is couched purely in terms of truth-apt episodes-any cognitivist account, as we might put it.

I'm unaware of the broad inertness argument being made explicit in the literature before. But the idea that it influences the pain debate is illuminating, not least because of a striking parallel between, on the one hand, views of moral evaluation taken by metaethicists who endorse the narrow inertness argument and, on the other hand, contemporary accounts of unpleasant pain in the philosophy of mind. In particular, just as many have invoked either desires or commands to capture the motivational force of moral evaluations, so the same ingredients-desires and commands-are invoked by the dominant accounts of pain's motivational character. I think the influence of the broad inertness argument explains why. 
We are at last ready for a plan of action. In §3-5, I consider two key noncognitivist accounts of unpleasant pain: the desire view and imperativism. I argue that neither accommodates unpleasant pain's rationalising role or badness. Hence I turn in $\S 6$ to a cognitivist version of the desire view: the dislike approach. While its appeal to evaluative content is a step in the right direction, the potential benefits are lost because it construes evaluations as experience-directed rather than body-directed. Hence in §7, I develop a view I call evaluativism, which makes the evaluations body-directed instead. Finally, I defend this approach from, among other objections, the broad inertness argument.

\section{The Desire View}

Hume, on some interpretations, was led by the narrow inertness argument to hold that moral evaluations are not merely a matter of judgement, but must somehow involve desires, construed noncognitively. ${ }^{10}$ Similarly, and I suspect for similar reasons, it is in terms of desires that many contemporary philosophers have accounted for pain's unpleasantness, for example David Armstrong, Richard Brandt, Richard Hall, Derek Parfit, George Pitcher, and Michael Tye. ${ }^{11}$ Here is the kind of thing they say:

\section{The Desire View}

A subject's being in unpleasant pain consists in the subject's (i) undergoing a certain neutral (i.e. nonhedonic and non-motivational) sensory experience (the pain), and (ii) having an experience-directed, non-instrumental desire for that pain (or a phenomenal feature it has) immediately to cease. (Call this an e-desire.)

${ }^{10}$ See Bricke 1996

${ }^{11}$ See Armstrong 1962 (93-4, 107-109) and 1968 (310-316); Brandt 1979 (38); Hall (1989: 644); Parfit 1984 (501); Pitcher 1970 (380); Tye 1995a (228) and 1995b (116, 135).
Desire theorists take pains to be neutral sensory experiences. ${ }^{12}$ Like pure perceptualists, they commonly take these to be disturbancerepresenting somatosensory perceptions; and like pure perceptualists, they may take the perceptions' phenomenal character to consist in possession of their representational content. But unlike pure perceptualists, desire theorists think these experiences count as unpleasant only if their subjects direct e-desires at them, only if their subjects want them (or phenomenal feature they have) to cease. In a slogan: your pain's unpleasantness consists in your wanting it to stop.

So on this view an unpleasant pain is a composite of a neutral sensory experience and a desire. This two-component structure enables a more straightforward treatment of pain asymbolia than pure perceptualists can offer, according to which the asymbolic has the sensory but not the desiderative component of unpleasant pain. Hence you and the asymbolic might have phenomenally identical pains, but only yours count as unpleasant because only you want the pain to stop. Nonetheless, verifying the hedomotive claims, the desire view allows that unpleasant pain - the whole composite-is motivational and bad.13 For unpleasant pain has as a component an unsatisfied e-desire, and edesires (the idea goes) are both motivational and such that their being unsatisfied is intrinsically bad. So the shape of the desire theorist's project is to explain the motivational and normative features of pain's unpleasantness in terms of the motivational and normative features of desire, to explain the fact that unpleasant pains rationalise and are bad in terms of the fact that unsatisfied e-desires rationalise and are bad.

But the project fails. Or so I want to argue. Others wield against it dissociation cases. ${ }^{14}$ But these merely generate an impasse. Faced with subjects who seem to be in unpleasant pain while lacking edesires, desire theorists can simply deny the unpleasant pain or insist e-desires are present, albeit inconspicuously. It can be admitted, for instance, that soldiers in the heat of battle are sometimes badly injured

${ }^{12}$ Alternatively, one could restrict "pain" to the whole composite, in which case, notice, asymbolics are not in pain. For discussion, see Bain 2011

${ }^{13}$ And it allows that this is so independently of further desires, for the e-desires in virtue of which unpleasant pain is motivational and bad are supposed to be components of unpleasant pain. Contrast the view that e-desires make unpleasant pains bad but not unpleasant. ${ }^{14}$ See Rachels 2000 
while apparently lacking e-desires. For desire theorists can plausibly argue that their injuries don't cause pain, perhaps because a processing gate closes in the heat of battle. As for asymbolics, who also appear to lack e-desires yet insist they do feel pain, the desire theorist can simply deny their pain is unpleasant. What about patients given morphine for chronic pain, who sometimes say their pain no longer bothers them; or masochists, who apparently seek pain in certain contexts? Desire theorists might deny unpleasantness in these cases too; or instead insist on the presence of e-desires. There is evidence, indeed, that morphine patients do want their pain to cease and are unbothered by it only in the sense of being no longer made anxious by it. As for the masochist, perhaps he too has an e-desire, albeit one that is defeated by, for instance, his stronger desire to believe his dominatrix seeks his suffering.

Desire theorists also need not be worried about converse cases in which it seems that an experience that is not unpleasant is nevertheless the object of an e-desire. They can allow, for example, that you might want a pleasant but distracting experience to cease, since a desire for an experience to cease so as to end the distraction is an instrumental desire, hence not an e-desire. What about the case in which, having warned you she is about to cut the back of your neck with a knife, a prankster presses against your skin not a knife, but an ice cube's edge? Mightn't your belief that a knife is causing your experience generate a strong desire for the experience to cease? Perhaps so, the desire theorist can reply, but in that case your experience will thereby be intensely unpleasant, despite its innocuous cause.

So the desire view can handle the usual objections. But there are deeper difficulties, as I shall now argue.

\section{E-Desires as Mere Inclinations}

How do desire theorists conceive of desires? They tend not to say. But it is not uncommon for philosophers to think of desires roughly as follows:

\section{Desires as Inclinations}

A desire that $\mathrm{p}$ is a state that either is or grounds its subject's disposition to act in whatever she believes to be the best way of making $p$ true. ${ }^{15}$

I'll call such dispositions, or their grounds, inclinations. In the case of inclinations that admit of no further mental characterisation that explains the disposition, I'll speak of mere inclinations. The question, then, is this: might desire theorists construe e-desires as mere inclinations? Might they, in other words, take the desire for one's own pain immediately to cease to merely be a state that either is or grounds its subject's disposition to act in whatever she believes to be the best way to make her pain immediately cease? Plugging this conception into the desire view would yield the following:

\section{The Inclination Approach}

A subject's being in unpleasant pain consists in the subject's (i) undergoing a certain neutral sensory experience (the pain) and (ii) being merely disposed (or in a state disposing her) to act in whatever she believes to be the best way to make that experience immediately cease.

So this is what you get if you plug a conception of e-desires as mere inclinations into the desire view. But it won't do. For the desire theorist's aim, recall, was to reduce the normative and motivational character of pain's unpleasantness to the normative and motivational character of e-desires. Yet, construed as mere inclinations, e-desires simply lack the required normative and motivational character. Or so I shall argue.

Starting with motivating reasons, my argument is this: pain's unpleasantness rationalises; mere inclinations don't; so pain's unpleasantness cannot consist in mere inclinations. Warren Quinn, in a quite different context, provides a useful illustration of the second

${ }^{15}$ See Smith 1994 (104-116) and Armstrong 1968 (152). 
premise: that mere inclinations don't rationalise (1993: 235-242) ${ }^{16}$ Suppose you want to understand my switching on a particular radio, but all you know about me is that I have, first, a general disposition to switch on any radios I believe to be off and, second, a belief that this particular radio is off but would be switched on if I moved my finger thus. While this knowledge might enable you to explain causally my switching on the radio, Quinn argues, it would not enable you to make rational sense of my behaviour in the perspectival way distinctive of reason-explanations. For it fails to disclose any reasons of mine for switching on the radios. Again, it provides you with no access to a perspective from which switching on the radio might have seemed reasonable to me. Perhaps if you knew that I expected that switching on radios would be pleasurable, you could rationalise my switching them on. But it is not enough to know merely that I am inclined to switch them on. And the reason it is not enough is that mere inclinations don't rationalise behaviour, not even in conjunction with beliefs about how to implement them.

The point, notice, is not that we never have mere inclinations, nor that we shouldn't call them desires, nor indeed that desires never rationalise. The point is simply that mere inclinations don't rationalise. Back in the pain case, then, a mere inclination of yours to end your pain would not rationalise your doing so. It would not rationalise your lifting your foot from the scalding bathwater, nor enable me to make sense of your doing so. Hence, since your pain's unpleasantness does do those things, your pain's unpleasantness cannot consist in a mere inclination.

The inclination approach fares no better regarding justifying reasons. While your pain's unpleasantness is bad for you-a good reason for removing your foot from the bathwater-it surely wouldn't be if it consisted in your being merely inclined to stop your pain. Your being merely inclined to stop your pain is not a good reason for stopping it. It might make you stop it, in some sense, but it will not make stopping it rational, not even defeasibly. For what is so bad in itself about being in a state that disposes you to act in whatever you

${ }^{16}$ I've reformulated Quinn's point in my terms. believe to be the best way to make your pain cease? Absent a good answer to that question, we must reject the inclination approach.

This problem might seem easy to fix. Locke once called desire an "uneasiness", and we sometimes talk of wanting things badly. ${ }^{17}$ Such talk might tempt us to say that some inclinations can rationalise and justify behaviour by dint of being themselves unpleasant. If your inclination to end your pain is unpleasant, and if acting on it will end the inclination and thereby its unpleasantness, then your inclination surely constitutes good reason to act on it, good reason to lift your foot from the scalding water. But I fear this won't save the inclination approach. For invoking the unpleasantness of desires or inclinations subverts the desire theorist's project. The project was to explain the normative and motivational features of pain's unpleasantness in terms of the normative and motivational features of unsatisfied desires. But this Lockean twist on the inclination approach reverses that order of explanation, explaining the normative and motivational features of unsatisfied desires in terms of the normative and motivational features of their unpleasantness. It simply invokes what it was supposed to explain.

So this noncognitivist version of the desire view-the inclination approach-fails. In §6, I turn instead to a cognitivist version. But, before that, there is second noncognitivist approach to consider.

\section{Imperativism}

In his account of moral evaluation, Richard Hare invokes not desires, but something more like commands (1952). Like Hume's, this metaethics too is echoed by an important view of pain's unpleasantness, one recently advanced by Colin Klein, Richard Hall, and Manolo Martínez. ${ }^{18}$ I call it imperativism:

${ }^{17}$ Locke 1689/1975. Relatedly, Schiffer describes a "reason-providing" desire to $\phi$ as a selfreferring "desire to $\phi$ to relieve the discomfort of that desire" (1976: 199).

${ }_{18}$ See Klein 2007, Hall 2008, and Martinez 2011. 


\section{Imperativism}

A subject's being in unpleasant pain consists in the subject's (i) undergoing a certain neutral sensory experience (the pain) and (ii) receiving a command from the "pain module" to stop doing whatever he is doing.

Like pure perceptualists, imperativists may allow that unpleasant pain can be accounted for entirely in terms of its representational content. But they take the mood of at least part of that content to be not indicative, but imperative. Unpleasant pains don't just inform; they command. Or rather, a processing module-the pain modulecommands, for example telling you to stop immersing your foot in the scalding bathwater (Hall 2008). And, the idea goes, it is by dint of this imperatival nature that unpleasant pains have the motivating and reason-giving force they have. ${ }^{19}$

On this characterisation, imperativists agree with desires theorists on a good deal. They take unpleasant pains to be composites ${ }^{20}$ and tend to construe these composites' neutral, sensory components (the pains themselves) as disturbance-representing perceptions. Like inclination theorists, moreover, they construe the other, hedonic component noncognitively. The difference is that imperativists characterise that component in terms not of desires, but commands; and, unlike e-desires, these commands make no reference to pain, but are rather action- or body-directed, commands not to stop the pain, but to stop doing what you're doing (Klein 2007) or to not have a given bodily disturbance (Martínez 2011). Notwithstanding these differences, however, imperativism risks failing in much the same way as the desire view: by invoking motivational states that are incapable of unpleasant pain's rational role. ${ }^{21}$

Recall that the unpleasantness of your pain is both a justifying and motivating reason for lifting your foot from the scalding bathwater. The question is whether the same can be said of your

${ }^{19}$ See Klein 2007 (525-528), Hall 2008 (533-534), and Martínez 2011 (76, 78, 83, 87).

${ }^{20}$ Klein's imperativism (2007) is an exception.

${ }^{21}$ For other objections, see Bain 2011. receipt of a pain-command to lift your foot. Why should receiving that command be a good reason-or even appear to you to be a good reason-for lifting your foot? Both imperativism and the desire view invoke inclinations; and while imperativism explains the inclinations in terms of the subject's receipt of certain commands, my worry is that this explanation does nothing to illuminate what the desire view left unexplained: how the inclinations rationalise or justify action. ${ }^{22}$

Imperativists might protest that unpleasant pains are special commands, comparable to commands shouted so loudly that they make your ears hurt. We should obey them simply to prevent further unpleasant commands, the idea goes. But this reply suffers just the same problem as the Lockean twist on the inclination approach. For the imperativist project, recall, is to explain the reason-giving force of pain's unpleasantness in terms of the reason-giving force of commands. But the shouted command model reverses that order of explanation, explaining the reason-giving force of the commands in terms of the unpleasantness of receiving them. It invokes just what was supposed to be explained. Again, imperativists claim that pain-commands constitute unpleasant pains, and we have objected that such commands couldn't give us the reasons that unpleasant pains give us; hence it would clearly be question-begging for imperativists to reply that such commands do give us reasons by dint of their being unpleasant pains.

How else might imperativists defend the reason-giving force of pain-commands? Perhaps they will appeal to the pain module's authority, arguing that the module is not a capricious dictator, but rather a reliable-if fallible-guide to how to avoid and limit bodily damage. You will generally do much better if you obey your pain module's commands, the idea goes, and that is both a good reason for obeying and-if you're aware of it-a motivating reason too.

But suppose an evil genius operated on your brain long ago so that you are caused unpleasant pain only by your skin being gently and harmlessly touched. ${ }^{23}$ Hence, whereas bodily damage and its threat always fail to cause you unpleasant pain, your lover's tender

${ }^{22}$ On some views of desire, imperativism is a desire view, though not one invoking edesires.

${ }^{23}$ In cases of allodynia, pain is caused by (though not only by) such innocuous stimuli. 
caresses are agonizing. Now, that is surely an excellent reason to stop them, notwithstanding their presenting no bodily threat; and it would be easy to understand your trying to do just that. But imperativists who embrace the authority reply must demur. For the evil genius has utterly severed any connection between your obeying your pain module's commands and your avoiding bodily damage. So if imperativists take that connection to underpin the reason for your obeying your pain module, they must regard that reason as having been eliminated; and if you know about the operation, they must be perplexed by your trying to stop the caresses. But this is surely wrong: the agony of the caresses is plainly good reason to stop them, and it makes good sense of your trying to do so. In short, the reliability reply makes the justifying and motivating reasons that unpleasant pains provide entirely contingent on matters on which they are surely not entirely contingent.

Putting it another way, one reason unpleasant pains give us to, for instance, step out of the scalding bathwater is to end the unpleasant pain itself. After all, if you cannot remove your foot from the scalding water, then you have good reason to take painkillers instead. This is what imperativists cannot explain. Your pain, they think, is commanding you to stop doing what you're doing. But taking the painkillers involves silencing rather than obeying that command; and what reason is there to silence it? What is so bad about being told to stop doing what you're doing? The shouted command model initially seemed to answer that question; but it turned out merely to beg it. Imperativism, I conclude, must be rejected.

\section{E-Desires as Evaluations}

We've now rejected two noncognitivist views: imperativism and the inclination version of the desire view. But there is another way of taking the desire view, to which I now turn. It won't save noncognitivism, since it construes e-desires as truth-apt; but for the moment let's set aside the Humean hackles this will raise and see what can be made of the view.
Dennis Stampe, Warren Quinn, Tim Scanlon, Graham Oddie, and others think of desire as an evaluative phenomenon. ${ }^{24}$ At a rough approximation, one version of the view says this:

\section{Desires as Evaluations}

A desire that $p$ is an impression that it would be good if $\mathrm{p}$.

If you want to win the lottery, this view says, your desire's content is not that you will the lottery, but that it would be good if you did. Your desire is not a belief or a judgement to that effect, but a passive episode-something more in the way of an experience-in which it strikes you, or is impressed on you, that it would be good if you won. Thus construed, desires are truth-apt. ${ }^{25}$

Might the desire view construe e-desires along these lines? Might it, in other words, construe a desire for one's own pain immediately to cease as an impression that it would be good if one's pain immediately ceased-or, as I shall put it, bad if one's pain continued? Plugging this conception into the desire view would yield the following:

\section{The Dislike Approach}

A subject's being in unpleasant pain consists in the subject's (i) undergoing a certain neutral sensory experience (the pain), and (ii) undergoing an impression that it would be bad if the pain continued.

I call this the dislike approach, since desire theorists often identify one's desire for one's pain to cease and one's disliking it, ${ }^{26}$ which identification strikes me as (at least) more plausible when the desire is

\footnotetext{
${ }^{24}$ Stampe 1987, Quinn 1993, Scanlon 1998, and Oddie 2005. See also Helm 2002 and Anscombe 1957.

${ }^{25}$ On standing rather than occurrent desires, see Helm 2002 (22) and Oddie 2005 (56). ${ }^{26}$ Armstrong 1962 (93), Parfit 1984 (501), Pitcher 1970 (380), and Tye 1995a (228).
} 
construed as an evaluation. Hence a new slogan: your pain's unpleasantness consists in your disliking it.

Does this cognitivist view fare better than its noncognitivist predecessors? It has one crucial advantage: unlike mere inclinations, evaluative states do look capable of rationalising action. Recall the radio case. If you know that $\mathrm{I}$ am in a state in which I am not merely disposed to switch on radios, but am rather struck that it would be good if I did, you can begin to access the perspective from which my switching on radios seemed rational to me. So too, crucially, in the pain case: if I know not merely that you were disposed to end your pain, but that the continuation of your pain struck you as bad, I get a better grip on your reason for lifting your foot from the scalding bathwater. So evaluative content is a promising ingredient for an account of pain's unpleasantness.

But the dislike approach gets the recipe wrong. To see why, consider the following:

\section{The Euthyphro Questions}

(A) Is it the case (i) that your pain is represented as bad because it is bad, or (ii) that your pain is bad because it is represented as bad?

(B) Is it the case (i) that you dislike your pain because it is unpleasant, or (ii) that your pain is unpleasant because you dislike it?

While (i) is more plausible in each case, dislike theorists are committed to (ii). To see this, start with (A). Your pain is bad because unpleasant, surely, and the dislike view says it is unpleasant because it is disliked in the sense of striking you as bad. So the dislike view is committed to your pain's being bad because you represent it as bad, hence committed to your impressions of your pains' badness being self-verifying, incapable of incorrectness. That commitment strikes me as highly problematic. Recall, after all, that the dislike approach is cognitivist. The impressions of pain's badness that the view invokes to explain unpleasantness are supposed to belong to a category of contentful, truth-apt representations, representations that are criticisable if falsecriticisable if whatever they represent as $\phi$ is not $\phi$. But impressions of pain's badness could not be truth-apt, I suggest, if they were selfverifying -if, again, your pain's seeming bad made it bad. The worry is that episodes whose job is to present to their subjects how things are must be such that they could have been false; they must be such that the classificatory mechanisms implicated in them could have gone wrong. So I reject the dislike approach.

In response, my opponents might propose counterexamples to my anti-self-verification principle. I address these elsewhere (Bain 2009) and will not pursue the point here. But at least this much is clear: if you reject self-verifying impressions, you must reject the dislike approach. And, crucially, even if you do not reject self-verifying impressions, there are other reasons to worry. Two of these arise from question (B): committed to pain's being unpleasant because it's disliked, dislike theorists cannot say what it is most natural to say: that we dislike pain because it is unpleasant; it is unclear, moreover, how else they are to explain pain-dislike.

Responding to the latter worry, Hall provides two explanations of pain-dislike. ${ }^{27}$ Since pain tends to be caused by bodily damage, he argues, pain-dislike will be favoured by natural selection. Moreover, since subjects associate their pain with bodily damage, he thinks pain-dislike also arises by means of the sort of mechanism that causes one to dislike the taste of whisky after one is made sick by too much of it. This associationist explanation, he thinks, is supported by cases where associations between pains and their evaluatively conceived causes reduce, rather than increase, the dislike. According to Henry Beecher's famous study, soldiers hospitalised during the 1944 Anzio landings felt less pain-and less unpleasant pain - than civilians with similar injuries. Following Beecher (1959: 165), Hall suspects this is because the soldiers regarded their injuries as good for having saved them from the horrific battlefield. A similar mechanism might be operative in the ice cube prank, if your dislike of your experience lessens on discovering its cause to be an ice cube rather than a knife. So Hall has something to say by way of explaining our dislike of pain.

${ }^{27}$ In a paper (1989) written before he embraced imperativism. 
But even if Hall's explanations are plausible, ${ }^{28}$ notice something crucial: they can be given an hedonic reading, a reading on which the given associations and selective pressures do indeed influence our dislike of pain, just as Hall says, but do so by influencing our pain's unpleasantness, which Hall of course cannot allow. Presently I shall argue that my own account of pain's unpleasantness enables just such an elaboration of these explanations, which I shall argue is preferable to Hall's, not least (though not only) because it allows that we dislike our pains because they are unpleasant. In sum, while dislike theorists have something to say about why we dislike our pains - and to varying degrees - we can do better.

What has finally emerged from our discussion of the two versions of the desire view, then, is a dilemma. If e-desires are evaluations, they are problematically self-verifying and cannot be explained in the most natural and plausible ways. If e-desires are not evaluations, they cannot provide the good and motivating reasons that pain's unpleasantness does. So each conception of e-desires generates difficulties. It might be suggested that the dilemma's second horn can be made playable by some third conception of desire, on which edesires are neither evaluations nor mere inclinations. But while there are such conceptions, I suspect my objection to the inclination approach will also make them unsuitable for the desire theorist. For I suggest that construing e-desires in any non-evaluative way will prevent them from constituting the kinds of reasons unpleasant pains constitute. It is time, then, to look beyond the desire view.

\section{Evaluativism}

The dislike approach appealed to episodes that rationalise action in virtue of their evaluative content. That was surely a step in the right direction. The reason the view ran into trouble was that it took those

${ }^{28}$ Wall (1979) and Melzack et al (1982) are sceptical of Beecher's explanation of the Anzio case given that people often fail to feel pain until a considerable time after an injury, even in more mundane circumstances, and even when they conceive of the injury negatively. There is more to be said, but here my point is simple: if Beecher's explanation is right, my account of pain's unpleasantness handles it better than Hall's dislike approach. episodes to be experience-directed (a mistake imperativism avoided but only in a way that caused it problems of its own). Hence it might seem that what is needed is a view that invokes evaluative impressions that are not experience-directed, but body-directed. That, I think, is exactly right. Hence I propose the following:

\section{Evaluativism}

A subject's being in unpleasant pain consists in his (i) undergoing an experience (the pain) that represents a disturbance of a certain sort, and (ii) that same experience additionally representing the disturbance as bad for him in the bodily sense. ${ }^{29}$

So I claim - as desire theorists and imperativists may agree - that when you step into the scalding bathwater you're in pain by dint of perceptually representing your foot as undergoing a disturbance of a certain sort. But I insist that the pain is unpleasant and motivating only because it further represents that bodily disturbance as bad for you. If, stepping into the same water, an asymbolic has a pain that is not unpleasant, that is because, even though the represented disturbance is bad for him, his pain fails to represent it as such; his pain lacks that layer of evaluative content. ${ }^{30}$

Although my view is another composite view, there is a crucial difference between my composites and the noncognitivists'. Queasy about the idea of motivational, truth-apt episodes, the components into which noncognitivists tend to divide each unpleasant pain are either truth-apt and inert, or non-truth-apt and motivational. That is precisely not my picture. I concede that unpleasant pains comprise both non-motivational and motivational components, but my point is that even the motivational component is truth-apt.

What is badness in the bodily sense? One answer is that a disturbance's being bad in that sense is simply its being apt to harm the

${ }^{29}$ Other evaluativists include Helm (2002), Tye (2006) - who has apparently jettisoned his earlier dislike view - and Cutter (Cutter and Tye 2011).

${ }^{30}$ Given an evaluative view of desire, evaluativism can also be elaborated as a desire view, on which pain's unpleasantness consists in dislike not of pain, but of certain bodily states. 
subject's body, in the sense of being apt to impede its proper functioning. ${ }^{31}$ Another says that a disturbance's being bad additionally requires that the subject care about his proper functioning. ${ }^{32}$ Here I shall not pursue the question further. Nor is this the place to provide a psychosemantics to explain how bodily badness gets to be experientially represented..$^{33}$ For while these are important questions, they have been discussed elsewhere, and I want instead to devote the space remaining to challenges arising from this paper's core theme: the motivational and rational force of pain's unpleasantness.

First, though, let us appreciate evaluativism's virtues. Like the dislike approach, evaluativism credits pains with evaluative content, which I've argued promises to make better sense of unpleasant pains' status as reasons than either commands or mere inclinations could. But, unlike the dislike approach, evaluativism takes the relevant evaluations to be not experience-directed, but body-directed; they are evaluations not of pains, but of bodily disturbances. One benefit of this is that it helps us to escape the dislike theorist's commitment to selfverifying impressions. It is true that, on my view, when you step into the scalding bathwater something's being represented as bad constitutes something's being bad. But the things respectively represented and constituted as bad are different. It is the disturbance in your foot that is represented as bad, but your pain that this evaluative content renders bad. Crucially, moreover, these are different senses of "bad". Your foot is represented to be bad in the bodily sense; your pain is rendered bad in what we might call the experiential sense-that is, the sense invoked by the first of our hedomotive claims, according to which unpleasant pain is intrinsically bad for its subject.

${ }^{31}$ Notice that rejecting this answer would allow us, attractively, to take such aptness to harm to be the "disturbance" that pain's neutral component represents. (Recall I've been using "disturbance" as a mere place-holder for whatever that component represents.)

${ }_{32}$ Cutter and Tye give the former answer (2011: 99), Helm the latter (2002: 23). In "An 32 Cutter and Tye give the former answer (2011: 99), Helm the latter (2002: 23). In "An
Evaluativist Account of Asymbolia" (in preparation), I suggest that pain asymbolics might be incapable of experiencing bodily states as bad for themselves on account of lacking the appropriate kind of care.

${ }_{33}$ Cutter and Tye give a "tracking" psychosemantics (2011: 91), whereas Helm requires a "background concern" for (in one kind of case) "one's safety and integrity" (2002: 23).
A second benefit of substituting body-directed for experiencedirected evaluation is that we can improve on Hall's explanations of pain's unpleasantness and its variations. Recall the hospitalised Anzio soldiers. According to Hall, a soldier's positive judgement about his injury or disturbance-that it saved his life by removing him from the battlefield-reduced his dislike of the disturbance-representing experience, which in turn constituted a reduction in his pain's unpleasantness. But if the soldier's positive judgement did indeed reduce his pain's unpleasantness, ${ }^{34}$ we evaluativists can tell a better story about how it did so. For we can say that the soldier's positive judgement about the disturbance reduced how bad he experienced the disturbance to be, which constituted a reduction in his pain's unpleasantness, which in turn reduced his dislike of that pain. Why is this preferable to Hall's story? For two reasons. First, while it agrees with Hall that a disturbance-evaluating judgement might reduce an experience-directed state of dislike, it illuminates the mechanism of that reduction-in a way that Hall cannot-by parsing it into two processes of familiar kinds: on the one hand, a disturbance-evaluating judgement cognitively penetrating a disturbance-evaluating experience; and, on the other, a reduction in an experience's unpleasantness reducing the subject's dislike of the experience. Thereby - and this is the second advantage-it vindicates the intuition that one reason we dislike pains is that they're unpleasant.

Evaluativism, in short, is a promising response to our challenge. ${ }^{35}$ But in the next and final section, I consider three neglected difficulties it faces. These are serious; but they are not fatal. Indeed, on closer inspection, they highlight further virtues of evaluativism.

${ }^{34}$ See note 28 above.

${ }^{35}$ Evaluativism also promises a straightforward account of the intensity of pain's unpleasantness, which imperativism fails to do (see <suppressed $>$ ). 


\section{Defending Evaluativism}

(i) Broad Inertness

The elephant in the room is the broad inertness argument, encountered in §2. It appeared to show that, as motivational states, unpleasant pains could not be what we evaluativists say they are: namely, purely truth-apt.

How to respond? We could deny unpleasant pains' motivational character. But that is unappealing. Some think akrasia undermines the idea that moral evaluations are motivational; but it's unclear that an analogous phenomenon exists in the case of unpleasant pain. Certainly, asymbolia does not fit the bill because asymbolics' pains aren't unpleasant. And while it is true, of course, that suffering subjects might remain stationary, this can be explained in numerous ways: in some cases, a subject might lack any idea how to act so as to achieve her unpleasant pain's aim; in other cases, her unpleasant pain might itself motivate her to remain still; and in yet other cases, it might motivate her to move but be defeated by some stronger motivation. So, instead, I propose that we reject broad inertness.

Here there is not space to defend this strategy properly. But it is worth noting that Michael Smith's well-known argument for narrow inertness (the inertness of beliefs) fails to support broad inertness (in particular, the inertness of perceptions). Smith's argument can be reconstructed as follows:

\section{Smith's Argument for Narrow Inertness}

1. A belief that $p$ aims to fit the world in the sense that it tends to be eliminated by a perception that not-p.

2. If a belief that $p$ aimed to make the world fit it (i.e. was motivational, like a desire), then it would lack this tendency.

3. So a belief that $\mathrm{p}$ cannot aim to make the world fit it. (Smith 1994: 115-118.)
Grant for the sake of argument that this establishes the inertness of beliefs. Can we, by substituting "perception" for "belief" throughout, similarly establish the inertness of perceptions - which, crucially, are what evaluativists think unpleasant pains are? I think not. For the argument's first premise would be false; it would fail to capture the sense in which perceptions are truth-apt. ${ }^{36}$ A perception that $\mathrm{p}$ will not tend to be eliminated by a perception that not-p. A straight stick halfimmersed in water, for example, might look bent even while it feels not bent. Admittedly, if you lift the stick from the water, a visual perception of a bent stick will be followed by a visual perception of a straight stick, but this would be a case of one perception succeeding another-because of a change in the perceptual conditions-not of one perception eliminating another. In short, I suspect Smith's direction-offit argument for narrow inertness poses no threat to evaluativism.

Some will insist that there is nonetheless something objectionably "queer" about the idea of episodes that are both motivational and entirely truth-apt, even if they are experiences. But our version of that idea rather strikes me as utterly natural: when the badness for you of a state of your own body is impressed on you, this-independently of further desires-defeasibly motivates you to do something about that bodily state. In short, while there is far more to be said on both sides, the onus is on supporters of broad inertness to put it on a firmer footing.

There is also an ad hominem point to make: namely, that broad inertness is a problem for the desire view too. The dislike version of the desire view is cognitivist, after all. So if broad inertness is true, it is not only evaluativism that is undermined, but also the only version of the desire view which - by dint of its appeal to evaluative content-stood any chance of explaining unpleasant pain's rationalising role.

Admittedly, our opponents might make an ad hominem point of their own: if broad inertness is false, then pure perceptualism-on which feeling unpleasant pain is simply a matter of undergoing a perception of a certain bodily disturbance-is back in the running.

${ }^{36}$ Hence Smith's explanation of belief's direction-of-fit cannot be used to explain the sense in which perceptions are, as I've put it, truth-apt. 
Hence we must justify our preference for evaluativism. But that is easy: evaluativism's two-component structure handles the asymbolia case more straightforwardly than pure perceptualism, as we have seen; moreover, what is needed to make sense of the motivational, rational, and normative character of pain's unpleasantness is, I've argued, not just content, but evaluative content. ${ }^{37}$

\section{(ii) Capturing the Wrong Reasons}

A second worry: I complained in $\$ 5$ that imperativism misconstrues the reasons that pain's unpleasantness gives us; but it might seem that evaluativism does no better, indeed that evaluativism not only fails to accommodate the reasons unpleasant pain gives us, but takes unpleasant pain to provide reasons that in fact it doesn't. ${ }^{38}$ the following:

Beginning with the latter worry, our opponent might insist on

\section{(a) No Bodily Ends}

The end at which unpleasant pain, as a motivational state, is aimed is always the cessation of unpleasant pain itself and never the cessation of bad bodily states.

This would indeed undermine evaluativism as I have elaborated it. For my idea is precisely that unpleasant pains rationalise avoidance behaviour in virtue of presenting certain bodily states as bad, hence that unpleasant pains-as motivational states-are aimed at the cessation of those bodily states per se. To appreciate the worry, suppose that in the bath case you took an immediately effective painkiller instead of lifting your foot from the scalding water. This, the argument goes, achieved entirely the end at which your unpleasant pain was aimed, even if leaving your foot in the water risked injury. After all, once the painkiller took effect, there would have been no unpleasant

${ }^{37}$ See also (iii) below

${ }^{38}$ Talk of mental states giving or providing us with reasons is ambiguous between their presenting us with reasons and their constituting reasons, as we shall see. pain to motivate anything else. Hence (a) is true and evaluativism is undermined.

But the argument fails. As Wittgenstein notes, what would terminate a motivational state is not always what it is aimed at. I could end your desire for an apple by punching you in the stomach but that is not what you want (1975: 64). Similarly, an effective painkiller will indeed end your unpleasant pain, but that doesn't make ending your unpleasant pain your experience's aim, let alone its sole aim.

Our opponent might think that (a) is supported by the following:

\section{(b) Hedonic Ends}

Unpleasant pain is a justifying (i.e. a good) reason to act so as to end the unpleasant pain.

But while I accept (b), I deny that it supports (a). My picture is this. In taking the painkiller as you immerse your foot in the scalding bathwater, you are, as (b) says, doing something the unpleasantness constituted good reason to do. But your unpleasant pain also presents you with another good reason-your foot's bad state-to do something else, namely remove your foot from the water. And, in virtue of presenting you with that justifying reason, your unpleasant pain is, contra (a), a motivating reason to end that bodily state per se, a motivating reason that you merely silence-rather than act on-if all you do is take the painkiller. ${ }^{39}$

This picture is all the more plausible for rejecting (a). For we badly misunderstand the role of unpleasant pain if we think we can do everything it motivates us to do by taking painkillers. Evaluativism, then, is not undermined by (a). Indeed, its explanation of what is wrong with (a) is another of its advantages over the desire view. For the desire view claims that pain's unpleasantness is a matter of wanting the pain to cease; and this singularly fails to capture the idea

${ }^{39}$ Similarly, by presenting you with a reason to make amends, feelings of guilt can be motivating reasons, ones that you silence rather than act on if you succeed in forgetting what was making you feel guilty. 
that unpleasant pain is a motivating reason to do something about certain bodily states per se.

\section{(iii) Not Capturing the Right Reasons: Messenger-Shooting}

But even if we endorse (b), as I have said we should, can we really make sense of it? Imperativism, I argued, cannot; and evaluativism might seem no better off. For how might evaluativists explain why an episode representing your own body part as being in a state that is bad for you (in a bodily sense) should itself be bad for you (in an experiential sense)? What is so bad about being somatosensorily informed that your foot is in a bad state? Suppose you lack feet, and know your pain is a phantom limb experience. What is so bad about this experience informing you that the state of a foot you know you lack is bad for you? Why shoot the messenger if you know the message is false? Indeed, returning to the veridical case, why shoot the messenger even if you know the message is true?

It is tempting to reply by invoking unpleasant pains' effects. Thanks to their evaluative contents, unpleasant pains are often highly motivational, hence distracting and exhausting and in those senses bad. But this cannot be the whole answer. For there remains the challenge of making sense of unpleasant pains' intrinsic badness. A year-long orgasm would also be distracting and exhausting; and this would be a good reason to take a pill to stop it. But, when suffering unpleasant pain, there is a further reason for taking a painkiller: that the unpleasant pain is intrinsically bad. It is that which we need to accommodate.

A better response to the messenger-shooting objection, I suggest, is to bring out how natural and intuitive is the idea that its seeming to you that things are bad for you in some way can itself be bad for you in another way. Here, negative emotions such as grief and fear are instructive. Grief, I suggest, is a state it is intrinsically bad to be in, albeit defeasibly. It is not wrong or irrational to grieve, of course, and grief can have good consequences. But we nevertheless pity you when you grieve. Why? Because we recognise that grief is a state in which a death strikes you as bad-indeed awful-for you; and we recognise that something's striking you that way is itself bad for you. ${ }^{40}$ Again, grief's effects (e.g. exhaustion) can be bad, to be sure; but grief is also bad intrinsically -it is itself a kind of suffering - and this is so, I am claiming, because grief is a state in which a death strikes you as bad for you. ${ }^{4}$

Fear has a similar structure. Suppose you see a spider and are afraid. Your fear, I suggest, involves its striking you that your situation is dangerous, and in that sense bad for you. Again, your fear is not a mere consequence of things so striking you; nor does fear merely cause things to strike you that way; rather, fear is a state in which things so strike you. And that, I am claiming, is why fear is in itself bad for you, indeed a kind of suffering. In short, then, the cases of grief and fear should remind us how natural is the idea that it can be intrinsically bad for you (in one sense) to be in a state in which something seems bad for you (in another sense).

Our opponents might object that the grief and fear cases are red herrings. When you grieve or are fearful, they might say, things seem bad to you in the doxastic sense of "seems"; you believe they are bad. But the pain case is different. Even if your feeling unpleasant pain involves its seeming to you that a body part of yours is in a bad state, this is not a matter of your believing that the body part is in a bad state. After all, if you know the relevant body part has been amputated, and that your pain is a phantom limb experience, you will lack that belief. So even if we can understand why subjects believing that things are bad for them is itself bad for them, this tells us nothing about the pain case.

But I deny the disanalogy. "Seems" in the pain case is indeed non-doxastic; but it is non-doxastic in the emotion case too. The case of witting phobics parallels witting phantom limb subjects. You might fear the spider even while knowing it to be harmless, so even while not

${ }^{40}$ This is compatible with grief being bad because unpleasant, provided its unpleasantness consists in possession of its evaluative content.

${ }^{41}$ In a fascinating, if telegraphic, discussion, Korsgaard similarly compares grief and physical pain (1996: 145-155, esp. 154-155). But her view of pain is hard to nail down. She claims pain is a perception of bodily conditions and of reasons to change those conditions, which is redolent of evaluativism (1996: 148, n. 19, and 149-151). But other remarks of hers are more suggestive of the desire view (1996: 147-148, 154). 
believing your situation to be bad. But, fearing the spider, your situation still seems bad to you, in what must therefore be a nondoxastic sense of "seems". So "seems" is non-doxastic in both the pain and emotion cases, and the analogy holds. ${ }^{42}$

\section{$\operatorname{sen} \operatorname{sen} \cos c \operatorname{sis}$}

Evaluativism, then, has many virtues. Construed as body-directed evaluations, unpleasant pains are not self-verifying. They can rationalise behaviour, and not only behaviour directed at ending themselves. And yet we can understand why they are indeed bad in themselves, thus constituting good reasons for taking painkillers. Evaluativism, I conclude, is our most promising account of unpleasant pains. ${ }^{43}$

\section{References}

Anscombe, G. E. M. 1957. Intention (Oxford: Basil Blackwell).

Armstrong, D.M. 1962, Bodily Sensations (London: Routledge and Kegan Paul).

Armstrong, D.M. 1968. A Materialist Theory of the Mind (London: Routledge and Kegan Paul).

Aydede, M. 2005. Pain: New Essays on Its Nature and the Methodology of Its Study (Cambridge, Mass.: MIT Press).

Bain, D. 2009. "McDowell and the Presentation of Pains", Philosophical Topics, 37, 1-24.

${ }^{42}$ Alternatively, one might preserve the analogy by taking "seems" to be doxastic in both the pain and emotion case, if one thinks that perceptual seeming (even in the witting illusion and hallucination cases) involves belief constitutively (see Byrne 2009).

${ }^{43}$ For comments and discussion, I am extremely grateful to Murat Aydede, Michael Brady, Bill Brewer, Jennifer Corns, Frederique de Vignemont, Ruth Dick, Rose Drew, Kent Hurtig, Colin Klein, Manolo Mas, Fez, Dernot O'Keffe, Brend On Oullivan, Sebastiun Sanheza, Robert Schroer, Carolin Schulze, Barry Smith, Folke Tersman, and audiences at the Institute Jean Nicod, Paris, and at the Universities of Fribourg, Glasgow, and Uppsala. This paper was written while PI of Glasgow University's Pain Project, which is funded by Sam Newlands and Mike Rea's Problem of Evil in Modern and Contemporary Thought project, which is based at the University of Notre Dame and supported by the John Templeton Foundation.
Bain, D. 2011. "The Imperative View of Pain", Journal of Consciousness Studies, 18, 164-185.

Bain, D. In preparation. “An Evaluativist Account of Pain Asymbolia".

Beecher, H. K. 1959. Measurement of Subjective Responses (Oxford: Oxford University Press).

Brandt, R. 1979. A Theory of the Good and the Right (Ithaca: Cornell University Press).

Bricke, J. 1996. Mind and Morality: an Examination of Hume's Moral Psychology (Oxford: Clarendon Press).

Byrne, A. "Experience and Content", Philosophical Quarterly, 59, 429451.

Cutter, B. and M. Tye. 2011. "Tracking Representationalism and the Painfulness of Pain", Philosophical Issues, 21, 90-109.

Grahek, N. 2007. Feeling Pain and Being in Pain (2 ${ }^{\text {nd }}$ edn.) (Cambridge, Mass.: MIT Press).

Hare, R. M. 1952. The Language of Morals (Oxford: Clarendon Press).

Hall, R. J. 1989. “Are Pains Necessarily Unpleasant?" Philosophy and Phenomenological Research, XLIX, No. 4.

Hall, R. J. 2008. “If It Itches, Scratch!” Australasian Journal of Philosophy, $86,4,525-535$

Helm, B. 2002. "Felt Evaluations: A Theory of Pleasure and Pain", American Philosophical Quarterly, 39, 1, 13-30.

Hume, D. 1739/1978. A Treatise of Human Nature, ed. L. A. Selby-Bigge and P. H. Nidditch (Oxford: Oxford University Press), $2^{\text {nd }}$ edn.

Klein, C. 2007. “An Imperative Theory of Pains”. Journal of Philosophy, $104,10,517-32$.

Korsgaard, C. 1996. The Sources of Normativity (Cambridge: Cambridge University Press).

Locke, J. 1689/1975. An Essay Concerning Human Understanding (Oxford: Clarendon Press).

Martinez, M. 2011. "Imperative Content and the Painfulness of Pain" Phenomenology and the Cognitive Sciences, 10, 67-90. 
Melzack, Ronald, P. D. Wall, and T. C. Ty. 1982. "Acute Pain in an Emergency Clinic: Latency of Onset and Descriptor Patterns Related to Different Injuries", Pain, 14, 33-43.

Oddie, G. 2005. Value, Reality, and Desire (Oxford: Clarendon Press).

Parfit, D. 1984. Reasons and Persons (Oxford: Oxford University Press)

Pitcher, G. 1970a. "The Awfulness of Pain", Journal of Philosophy, 68, 481-92.

Pitcher, G. 1970b. "Pain Perception", Philosophical Review, 79, 368-393.

Quinn, W. 1993. "Putting Rationality in its Place", in his Morality and Action (Cambridge: Cambridge University Press).

Rachels, S. 2000. "Is Unpleasantness Intrinsic to Unpleasant Experiences?", Philosophical Studies, 99, 187-210.

Scanlon, T. 1998. What We Owe To Each Other (Cambridge, Mass.: Harvard University Press).

Schiffer, S. 1976. "A Paradox of Desire", American Philosophical Quarterly, 13, 195-203.

Smith, M. 1994. The Moral Problem. (Oxford: Basis Blackwell).

Stampe, D. 1987. "The Authority of Desire", Philosophical Review, 96, 335-381.

Tye, M. 1995a, “A Representational Theory of Pains and Their Phenomenal Character", Philosophical Perspectives 9: AI Connectionism, and Philosophical Psychology, 223-39.

Tye, M. 1995b. Ten Problems of Consciousness (Cambridge, Mass.: MIT Press).

Tye, M. 2006a. "Another Look at Representationalism About Pain", in Aydede 2006.

Tye, M. 2006b. “In Defense of Representationalism: Reply to Commentaries", in Aydede 2006.

Wall, P. D. 1979. “On the Relation of Injury to Pain”, Pain, 6, 253-264. Wittgenstein, L. 1975. Philosophical Remarks (Oxford: Basil Blackwell). 